\title{
Philosophical aspects and analysis of the regularities of formation of geo-economic thinking
}

\author{
Ubaydullayev Islomjon Abdullayevich ${ }^{1}$ \\ ${ }^{1} \mathrm{PhD}$, Senior teacher of Namangan institute of engineering and technology, \\ Uzbekistan (Ubaydullayev-76@mail.ru)
}

\begin{abstract}
In this article some philosophical aspects of the interpretation of the geo-economical thinking and consciousness of the owners in general are considered. There is the analysis some features and peculiarities of the revealing of this kind of thinking in the sphere of global economy and local markets is provided.

Keywords: geo-economic thinking, society, social philosophy, world economy, processes of globalization, economic thinking, economic culture, the class of owners, geo-economic thinking of the owners, geo-economic concepts, ontological and epistemological foundations.
\end{abstract}

\section{Introduction}

Geo-economic processes in the world economy require of each owner to quickly comprehend the logic of their development and create their own relationship of trade turnover. The notion of geo-economic logic of development of processes is done through geo-economic way of thinking.

Thus, if the social entity will consist of a set of processes and events designed to meet the needs of the people and created by their practical activity, social consciousness is a reflection of the natural and social reality, a complex of sensations, sentiments, opinions, ideas, theories that apply to a specific period of society. As social consciousness can be divided into several forms, based on their reflection on events and processes of social nature, such as economic, political, moral, legal, aesthetic, environmental, etc.

\section{Main part}

Taking as a methodological basis of the characteristics given to the notion of social philosophy the subject of consciousness, it is possible to give the following definition of economic consciousness. Economic consciousness, as a form of social consciousness is a unified system of theories and thoughts, attitudes, ideals, ideas, sensations, passions, aimed at feeling, mental awareness and a change in future economic and spiritual life of the present society, particularly economic relations that arise between people.

This definition also shows that economic consciousness incorporates such qualities as knowledge of emotional and mental thinking. Here is a special place in economic thinking.

Russian scientist L. N. Ponomarev, Uzbek scientist B. Valiev give the following definition of the notion of economic thinking: "From the point of view of the philosophy the economic thinking is the main form of display of economic events, appropriate knowledge and generalizing important links in economic relations, create new ideas, an awareness of the trends of economic events and processes. This process of display of economic relations and events in such forms of thought, as an idea, concept, judgement, conclusion. It is the promotion and development of thought, associated with the formation of certain economic ideas, knowledge, views, attitudes towards economic reality" $[1 ; 2 ; 4]$. Based on this idea and on the assumption, to the knowledge of some aspects of economic processes it applies economic thinking can be divided into macroeconomic thinking, microeconomic thinking, national economic thinking, geo-economic thinking, geo-finance thinking, ethno-economic thinking, external economic thinking, etc.

Geo-economic thinking is one of the forms of economic thinking, dialectical reflection of such forms of thought, notion, judgment, conclusion, in the form of ideas, ideals, attitudes, thoughts, actions taking place in the geo-economic space of the economic, political, legal, and spiritual processes of all actors who have economic relations on the world market. In particular, this system of modern mental activity, which embodies the theoretical and practical knowledge, experience and skills acquired to generate profit based on knowledge of trends in the process of trade turnover.

The process of formation of geo-economic thinking incorporates the following two features:

The first feature is linked with the task of forming a geo-economic thinking in consciousness of the person and contains the following two directions, on the one hand, on the empirical level by feeling in connection with direct vision, the challenge of ongoing economic relations between states and economic processes taking place in the world, on the other hand, absorbs the work on formation at the level of theoretical and practical knowledge by studying books, articles, scientific journals and other literature, which reflects the economic knowledge accumulated by society.

The second feature is linked with the ways and means for the organization of the formation in the mind of the people geo-economic thinking on the one hand includes the formation of geo-economic thinking in the property class, which is the direct subject of geo-economics, on the other hand, the organization works to improve geo-economic thinking of the country's population. These two features complement each other and constitute two relative sides of one whole.

The main driving force of geo-economics is the class of owners. That is why the problem of 
formation of geo-economic thinking in the property class is included in the number of urgent tasks, which have strategic importance to our government.

According to the material and spiritual life trends of dialectical thinking the geo-economic thinking of the class of owners has ontological and epistemological foundations.

Ontological foundations of geo-economic thinking of the class of owners consists of [6]:

- at first, the presence of material and spiritual property, the possession of such property by owner, and also enjoy the benefits of this property by the society by the established norms;

- secondly, the quantity and quality of the property accumulated in the hands of the owner;

- thirdly, the share of profit received from economic relations between the owners, both inside and outside the state;

- fourthly, the indicators of the quality and quantity of constructed facilities and technology imported and implemented in the production at the expense of the profit;

- fifth, is the real existence of the world markets of the goods and the value of the material nature of the turnovers that occur in such markets.

The epistemological foundations of geo-economic thinking of the class of owners consists of

1) economic thinking of the owner and its levels;

2) the scientific potential of the owner;

3) the skill and initiative, the entrepreneurial spirit of the owner;

4) the ability of the owner to the knowledge of the existing economic space;

5) the spiritual world of the owner, etc.

As can be seen from the above, geo-economic thinking of the class of owners consists of mutual unity of the objective aspect -subjective and ontological-epistemological.

The main directions of formation of geo-economic thinking owners are comprised of the following of the geopolitical picture of the world today.

The geo-economic picture of today includes the following: firstly, a general description of the world's economic spaces resulting from the mutual influence of national and transnational spaces of the economy; secondly, interpretation in a convenient forms of a global economic space for the purposes of decision making, useful from the point of view of the strategies of states in international economic relations; thirdly, the division of global economic spaces on one particular areas and levels; fourthly, includes spaces obtaining the share of the world's income.

There is turns out that all the above features constitute the empirical base of the geo-economic thinking, and on the basis of its logical mind, judgment and opinion of the economic thinking.

2. The formation of the geo-economic thinking through the formation of scientific knowledge and understanding of the geo-economic space and time.

From the above it follows that the geo-economic space is the location in a certain place of geoeconomic attributes, such as weight of goods, barter, market, and also the profit and income; the geo-economic time is interval sequential relationships in a certain time interval of the geo-economic attributes. Thus, the geoeconomics exists only in a particular time and space as a socio-economic event.

Only if the class of owners will have accurate knowledge about the geo-economic picture of the modern world, existing in the geo-economic space and time, they will be able to get profit and revenues from sales of their goods on the world market. And this can only be achieved by seeing a ray of light of the geoeconomic thinking.

Today, any country and any society social groups and individuals are not perceived as closed and selfsufficient phenomena. They are included in the general relationships and interdependence.

General interrelation, interdependence and relationships are a natural extremely complex and contradictory processes of the globalization.

The globalization is universal and multilateral process of cultural, ideological and economic integration of states, state associations, national and ethnic unities, which represents a concomitant phenomenon of modern civilization.

Universal processes of globalization cause the necessary and deep changes in the rapprochement and mutual cooperation of nations and states. This is followed by a process of convergence and harmonization of standard of living and its quality.

The main characteristic of the process of globalization occurring in the modern world - extrapolation of liberal-democratic values in all regions without exception. This means that political, economic, legal, etc. systems of all countries of the world become identical, and the interdependence of countries is already reaching unprecedented proportions. Still peoples and cultures has never been so dependent from each other. The problems arising anywhere in the world, instantly reflected on the rest of the world.

The process of globalization and homogenization leads to the creation of a single world community, in which are formed a unified norms, institutions and cultural values. There is a feeling of the world as a single 
place.

The process of globalization is characterized by the following main aspects:

1. Internationalization that is expressed in the relationship primarily;

2. Liberalization, i.e. the removal of trade barriers, mobility of investments and the development of integration processes;

3. Westernization as the extrapolation of Western values and technologies anywhere in the world;

4. Deterritorialize that resulting in activity that was transnational in scope, and reducing the significance of state borders.

The globalization involves the formation of a common international economic, legal and culturalinformation space, and its phenomenon cannot be exhausted in the economic frameworks and has a significant impact on all basic spheres of social life - politics, ideology and culture.

In our view, an integrated assessment of this phenomenon has not yet stated, but in spite of this, it can be argued that this process will play a decisive role in the world economy of the XXI century.

The globalization is one of the few economic categories, the rating which went far beyond the purely professional frameworks, with evaluation on both a professional and at the everyday level is not straightforward. In our view, only its objective nature cannot be questioned.

The most important methodological position is a deep interrelationship and interaction between the categories of "globalization", "geo-economy", "internationalization of economic life," "international economic cooperation", "international economic relations", as well as the consequences of their interactions.

The globalization affects the economy of all countries. It affects the production of goods and services, use of labour, investments, technologies and their distribution from one countries in others. All this ultimately affects production efficiency, productivity and competitiveness. It is precisely globalization has caused the aggravation of the international competition. In the aftermath of the globalization in the sphere of the economy emerged the phenomenon of the geo-economics and associated with this phenomenon geo-economic processes.

\section{Conclusion}

Geo-economic processes in the world economy, require each owner to quickly comprehend the logic of their development, to create their own relationship of turnover and of course, the dialectics of the geoeconomics with the economy. The notion of geo-economic logic of development of processes is done through the geo-economic way of thinking.

\section{References}

1.Ponomarev, L. N. etc. Economic culture: (the nature, trends of development). - M.: Mys1, 1987. - 55 S.

2.Valiev B. Economic culture and factors of its development. -T: Publishing-polygraphic Association "Tashkent Islamic University". 2008. - 37 S.

3.Makhmudov E. R. World economy: contemporary economic system. - T: Umaid, 2004. - 528 p.

4.Ponomarev, L. N. etc. Economic culture: (the nature, directions of development) - M.: Mys1, 1987.- 269

p.

5.Haydarov F. Laws reform. - Tashkent: Uzbekistan, 2010. - 160 p.

6.Khakimov, A. A., Ubaydullaev I. A. Problems of formation of geo-economic thinking of the owners in the context of globalization // The young scientist. - 2014. -No. 6. - S. 873-875. 